\title{
Linking Lung Function to Structural Damage of Alveolar Epithelium in Ventilator-Induced Lung Injury
}

\author{
Katharine L. Hamlington ${ }^{1}$, Bradford J. Smith², Celia M. Dunn, Chantel M. Charlebois, \\ Gregory S. Roy, and Jason H. T. Bates ${ }^{*}$ \\ Department of Medicine, University of Vermont Larner College of Medicine, Burlington, VT 05405, \\ USA
}

\begin{abstract}
Understanding how the mechanisms of ventilator-induced lung injury (VILI), namely atelectrauma and volutrauma, contribute to the failure of the blood-gas barrier and subsequent intrusion of edematous fluid into the airspace is essential for the design of mechanical ventilation strategies that minimize VILI. We ventilated mice with different combinations of tidal volume and positive end-expiratory pressure (PEEP) and linked degradation in lung function measurements to injury of the alveolar epithelium observed via scanning electron microscopy. Ventilating with both high inspiratory plateau pressure and zero PEEP was necessary to cause derangements in lung function as well as visually apparent physical damage to the alveolar epithelium of initially healthy mice. In particular, the epithelial injury was tightly associated with indicators of alveolar collapse. These results support the hypothesis that mechanical damage to the epithelium during VILI is at least partially attributed to atelectrauma-induced damage of alveolar type I epithelial cells.
\end{abstract}

\section{Graphical Abstract}

Alveolar Epithelial Surface Damage After Ventilation with High Inspiratory Pressure and Zero End-Expiratory Pressure

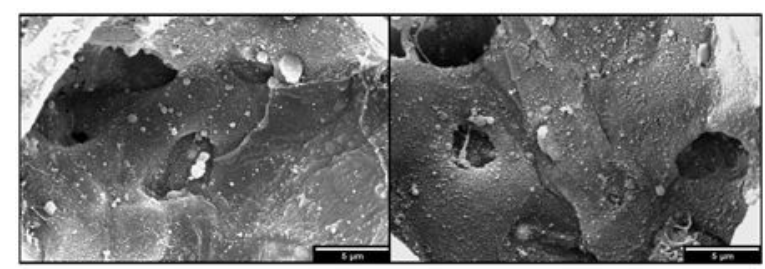

\footnotetext{
"Corresponding author at: University of Vermont Larner College of Medicine, 149 Beaumont Avenue, HSRF 228, Burlington, VT 05405-0075, USA, Tel: (802) 656-8912; Fax: (802) 656-8926, jason.h.bates@uvm.edu (J.H.T. Bates).

${ }^{1}$ Present Affiliation: Department of Pediatrics-Pulmonology, University of Colorado at Children's Hospital Colorado, Aurora, CO 80045, USA. katharine.h.smith@ucdenver.edu

2Present Affiliation: Department of Bioengineering, University of Colorado Denver | Anschutz Medical Campus, Aurora CO, 80045, USA. bradford.smith@ucdenver.edu
}

Conflict of Interest: J.H.T.B is a member of the advisory board and a minor shareholder in Oscillavent, LLC. No conflicts of interest, financial or otherwise, are declared by the remaining authors.

Publisher's Disclaimer: This is a PDF file of an unedited manuscript that has been accepted for publication. As a service to our customers we are providing this early version of the manuscript. The manuscript will undergo copyediting, typesetting, and review of the resulting proof before it is published in its final citable form. Please note that during the production process errors may be discovered which could affect the content, and all legal disclaimers that apply to the journal pertain. 


\section{Keywords}

acute respiratory distress syndrome; mechanical ventilation; alveolar epithelial injury; lung function measurement; scanning electron microscopy

\section{Introduction}

Mechanical ventilation is essential to the management of acute respiratory distress syndrome (ARDS), but it can also be deleterious by causing ventilator-induced lung injury (VILI) through two distinct mechanisms: overdistension of lung tissue resulting in volutrauma, and repetitive opening and closing of lung units resulting in atelectrauma (Gattinoni et al., 2010). These injurious mechanisms disrupt the blood-gas barrier (Dreyfuss and Saumon, 1998a), allowing plasma-derived fluids and proteins to accumulate in the airspaces of the lung where they inactivate surfactant and raise surface tension. The result is an escalation in the tissue stresses and strains wrought by mechanical ventilation, exacerbating the leak across the blood-gas barrier in a vicious cycle that is often fatal.

Ultrastructural studies using transmission electron microscopy (TEM) have confirmed that VILI involves damage to the distinct barriers presented by the endothelium and epithelium (Dreyfuss and Saumon, 1998a). The timing and degree of these events, however, apparently depends on the nature of mechanical ventilation. A number of animal studies have shown, for example, that over-distension leads rapidly to interstitial pulmonary edema, with epithelial damage manifesting somewhat later (Dreyfuss et al., 1985; Dreyfuss et al., 1988). On the other hand, our studies in mice have shown that breach of the epithelial barrier by volutrauma is greatly accelerated when atelectrauma is present at the same time, suggesting that these two injury mechanisms operate in distinct but complementary fashions.

Understanding how volutrauma and atelectrauma conspire to breach the epithelial barrier is thus of significant practical concern because this barrier presents the last line of defense against leaked material that elevates alveolar surface tension. Furthermore, it is this material that is responsible for the major mechanical derangements occurring in lung injury. Monitoring of lung mechanics thus has the potential to serve as a clinical indicator of VILI severity and progression. Accordingly, the goal of the present study was to determine how the altered lung mechanics characteristic of VILI are reflected in physical damage to the alveolar epithelial barrier. We generated VILI by applying graded levels of injurious mechanical ventilation to initially normal mice, and then used scanning electron microscopy (SEM) to directly assess physical damage to the alveolar epithelium, because this imaging technique is uniquely suited to visualizing surface topology and texture. We hypothesized that these surface features would change in quantifiable ways reflective of reduced barrier function in VILI, and that these changes would correlate with alterations in lung mechanical function. 


\section{Materials and Methods}

\subsection{Animal Procedures}

The Institutional Animal Care and Use Committee of the University of Vermont approved the study protocol. Animal treatment complied with the Animal Welfare Act. Twenty-seven healthy 8-10 week old 18-22 g BALB/c female mice (Jackson Laboratories, Bar Harbor, ME, USA) were anesthetized with $90 \mu \mathrm{g} / \mathrm{kg}$ intraperitoneal (IP) injection of sodium pentobarbital, tracheostomized, and ventilated with a flexiVent small animal ventilator (SCIREQ, Montreal, QC, Canada). Continuous anesthesia was maintained with $5 \mu \mathrm{g} / \mathrm{kg}$ IP sodium pentobarbital administered every $30 \mathrm{~min}$ with $0.15 \mathrm{ml} \mathrm{IP} \mathrm{5 \%} \mathrm{dextrose} \mathrm{lactated}$ Ringer's solution; deep anesthesia was ensured via EKG heart rate monitoring. $0.8 \mathrm{mg} / \mathrm{kg}$ IP pancuronium bromide was administered at the start of ventilation to prevent spontaneous breathing efforts that prevent accurate measurement of lung mechanics. Control animals were harvested immediately after tracheostomy without ventilation.

\subsection{Ventilation Protocol}

The mice received stabilizing ventilation for 10 minutes with PEEP $=3 \mathrm{cmH}_{2} \mathrm{O}$ and a tidal volume $\mathrm{V}_{\mathrm{T}} \approx 10 \mathrm{ml} / \mathrm{kg}$. Lung function assessments, consisting of a series of three derecruitment tests at $\mathrm{PEEP}=6,3$, and $0 \mathrm{cmH}_{2} \mathrm{O}$, occurred immediately after the stabilization period and again after ventilation. Each derecruitment test began with a recruitment maneuver ( $3 \mathrm{~s}$ ramp to $30 \mathrm{cmH}_{2} \mathrm{O}, 3 \mathrm{~s}$ breath hold) immediately followed by nine repetitions of the following: $2 \mathrm{~s}$ multi-frequency impedance measurement fit to the constant-phase model (Hantos et al., 1992) to yield elastance $(\mathrm{H})$ and $21 \mathrm{~s}$ of ventilation at $\mathrm{V}_{\mathrm{T}}=10 \mathrm{ml} / \mathrm{kg}$. After the initial assessment, ventilation commenced as described in Table 1 for $310 \mathrm{~s}$, followed by a pressure-volume (PV) measurement ( $3 \mathrm{~s}$ ramp to pressure $\mathrm{P}_{\mathrm{PV}}, 3 \mathrm{~s}$ hold, $3 \mathrm{~s}$ ramp down to ventilation PEEP) and two impedance measurements separated by $12 \mathrm{~s}$ ventilation at $\mathrm{V}_{\mathrm{T}}=10 \mathrm{ml} / \mathrm{kg}$. This ventilation-measurement process was repeated either 22 times or until $\mathrm{H}$ measured after the PV loop approximately either doubled or quadrupled from the value at the start of the ventilation period (Table 1).

\subsection{Sample Preparation}

Lungs were fixed in situ via airway instillation with Karnovsky's fixative (2.5\% glutaraldehyde and $1 \%$ paraformaldehyde in $0.1 \mathrm{M}$ cacodylate buffer) at a constant pressure of $20 \mathrm{cmH}_{2} \mathrm{O}$. The trachea was ligated to maintain inflation pressure, and the excised heartlung block was immersion fixed for a minimum of 24 hours at $4^{\circ} \mathrm{C}$. The left lung was ligated, embedded in $4 \%$ agar, and sliced transverse to the cranial-caudal axis from apex to base into $2 \mathrm{~mm}$ sections (Fig. 1). The resulting sections were trimmed to a size less than $4 \times$ $4 \mathrm{~mm}$. Three slices from each lung were selected for further processing using uniform random sampling (Schneider and Ochs, 2013). The selected slices were post-fixed in 1\% osmium tetroxide in $0.1 \mathrm{M}$ cacodylate buffer, dehydrated in a graded ethanol series, and critical point dried with liquid $\mathrm{CO}_{2}$ (Samdri-PVT-3D critical point dryer, Tousimis Research Corp., Rockville, MD). Samples were mounted onto aluminum stubs with conductive graphite and sputter coated in argon gas with gold and palladium (Polaron E5100 sputter coater). All processing was completed within one week. 


\subsection{Imaging}

Images were acquired with a JSM6060 scanning electron microscope (JEOL USA, Inc., Peabody, MA) at $10 \mathrm{kV}$ accelerating voltage, $8-10 \mathrm{~mm}$ working distance, and spot size 40. We implemented an unbiased sampling procedure of the lung slices as depicted in Fig. 1. Each slice was imaged at 50x magnification, and a grid with $200 \mu \mathrm{m}$ spacing was randomly oriented over the image using a custom program developed in Matlab (Mathworks, Natick, MA). All points covering parenchyma were selected, excluding those on large airways and blood vessels, and 18 of these points were selected via uniform random sampling as imaging points. The alveolar surface centered on the alveolar depression nearest each of these points was imaged at 5000 $\times$ magnification. Fifty-four images were acquired per animal yielding 216 images per group (378 images in HighP/ZEEP/2 $\times \mathrm{H}$ group). A series of $5000 \times$ images from unventilated controls and HighP/ZEEP mice were carefully analyzed to determine differences in alveolar surface characteristics in order to avoid confusing fixation artifacts with ventilation damage. We selected a set of features defining alveolar surface disruption. A blinded observer was trained on these features using a set of representative images of disrupted and non-disrupted surfaces. The images were scored as either having alveolar epithelial damage or having no damage. Statistical significance for group comparisons was accepted at $\mathrm{p}<0.05$.

\section{Results}

\subsection{Lung Function Assessment}

Animals in the HighP/ZEEP/4×H and HighP/ZEEP/2 $\times \mathrm{H}$ groups were ventilated until $\mathrm{H}$ measured during ventilation (Table 1) was approximately four or two times greater than the initial $\mathrm{H}$ measurement, respectively. The other experimental groups were ventilated for a fixed time because changes in $\mathrm{H}$ were small or nonexistent. The mean percent increase in $\mathrm{H}$ in the HighP/PEEP group, although significantly greater than zero (Student's t-test, $\mathrm{p}=0.02$ ), was nevertheless small and markedly less than the increases in the HighP/ZEEP groups (one-way ANOVA multiple comparison test using Tukey's Honestly Significant Difference Procedure, $\mathrm{p}=10^{-8}$ ). There were no significant differences in the mean changes in $\mathrm{H}$ between the HighP/PEEP, Low $\mathrm{V}_{\mathrm{T}} / \mathrm{ZEEP}$, and Low $\mathrm{V}_{\mathrm{T}} / \mathrm{PEEP}$ groups $(\mathrm{p}>0.2)$, and the changes were not different from zero in the latter two groups ( $\mathrm{p}=0.2$ and 0.08 , respectively).

Fig. 2 shows how corresponding values of $\mathrm{H}$ differed between derecruitment tests performed after each ventilation period versus those performed prior to ventilation. These differences were not significantly different from zero for the groups that did not sustain measurable injury (HighP/PEEP, LowVt/ZEEP, and LowVt/PEEP). The differences were substantial for the two HighP/ZEEP groups, however, with the greater differences seen in the $4 \times \mathrm{H}$ group; for both HighP/ZEEP groups, the mean change in $\mathrm{H}$ at each time point during the derecruitment tests was significantly different from the corresponding mean change in $\mathrm{H}$ for all other groups $(\mathrm{p}<0.01)$. There was no significant difference in the mean change in $\mathrm{H}$ in the other three groups. These findings show that lung injury was accompanied by widespread loss of ventilated alveoli (Lutz et al., 2015) due to significantly increased derecruitment pressures and rates (Massa et al., 2008; Smith et al., 2015). 


\subsection{Tissue Injury Assessment}

Representative micrographs of intact and damaged alveolar surfaces from the various study groups are shown in Figs. 3 and 4. Intact alveolar surfaces appeared either wrinkled with some surface coating or smooth, and often had sparsely distributed small particles (possibly resulting from airspace fixation) and well-defined cell junctions between type I alveolar epithelial cells (black arrows). Note the type II alveolar cells indicated by black stars. We defined ventilator-induced surface disruption as having the appearance of the epithelial surface peeling away to expose the cytoplasm or basement membrane. The white arrows in Figs. 4C and 4E indicate the distinct transition between intact (black circles) and disrupted surface (arrows point from the intact surface toward the disrupted surface). The damaged alveolar surface has a rougher texture and is littered with small particles, larger irregularly shaped cellular fragments, and interstitial components (white stars in Figs. 4C and 4E; entire surface is damaged in Figs. 4D and 4F). These rough surfaces show that the apical and/or basal cytoplasm has fragmented or been torn away completely and stand in stark contrast to the healthy alveolar surfaces (Figs. 3, 4A, and 4B). Features of ventilator-induced surface disruption were not present in any images from the Control or Low $\mathrm{V}_{\mathrm{T}} / \mathrm{PEEP}$ groups (Figs. $3 \mathrm{~A}-3 \mathrm{D}$ ) and were rarely observed in the Low $\mathrm{V}_{\mathrm{T}}$ /ZEEP (Figs. 3E and $3 \mathrm{~F}$ ) and HighP/PEEP (Figs. 4A and 4B) animals. The intact epithelial surfaces of the ventilated groups were generally smoother than those of the controls as is shown in the surface texture variation between Fig. 3A (unventilated control) versus Fig. 3D (Low Vt/PEEP ventilation). Although we sought to minimize fixation artifacts through careful technique and expedient processing, some surfaces in both the control and the ventilated groups had small holes or cracks resulting from fixation and dehydration; this was not considered ventilation damage (black squares).

The fraction of the 54 images from each mouse with a positive alveolar surface damage score is shown in Fig. 5A. Damage was significantly higher in the HighP/ZEEP/4×H group than in the HighP/ZEEP/2 $\times \mathrm{H}$ group, which, in turn, was significantly greater than damage in both the HighP/PEEP and Low Vt/ZEEP groups (one-way ANOVA multiple comparison test using Tukey's Honestly Significant Difference Procedure, $\mathrm{p}<10^{-6}$ in all cases). Neither of these latter two groups had a mean significantly different from zero (Student's t-test, $\mathrm{p}=0.1$ and 0.4, respectively). No images from the Low Vt/PEEP and Control groups scored positive for damage (data not shown). The percentage of images with epithelial damage from each slice is shown in Fig. 5B (symbol shapes for each animal are consistent with Fig. 5A). Slices 1,2 , and 3 in each group correspond to the slices taken from the upper, middle, and lower third of the left lung from each mouse (Fig. 1). The mean fraction of damaged images was not significantly different across slices in the HighP/ZEEP/4 $\times \mathrm{H}$ group. In contrast, in the HighP/ZEEP/ $2 \times \mathrm{H}$ group the mean damaged fraction for the apical slice was significantly greater than the fraction from the two lower slices $(\mathrm{p}<0.003)$. Although the first and third slices of the HighP/PEEP group and the first slice of the Low $\mathrm{V}_{\mathrm{T}}$ /ZEEP group did have a small number of images with epithelial damage, the mean damaged fractions were not significantly different from zero ( $\mathrm{p}=0.09,0.4$, and 0.4 , respectively).

Fig. 6 links epithelial damage to altered lung function by showing the percent change in the first $\mathrm{H}$ measurement during the $\mathrm{PEEP}=0$ derecruitment test ( $\mathrm{H} 1$, circled values in Fig. 2 ) as a 
function of the percentage of SEM images showing epithelial injury for each mouse. A straight line fit through these points explains $91 \%$ of the variance in $\mathrm{H} 1$ percent change, with $\mathrm{r}=0.96\left(\mathrm{p}<1 \times 10^{-12}\right)$. The change in $\mathrm{H} 1$ was not statistically significant different from zero for those animals with no images showing injury (y-intercept $=-6.6 \%, 95 \% \mathrm{CI}[-21 \%$, $7.7 \%]$ ). Each $1 \%$ increase in the number of images with damage corresponds to an average $3.1 \%$ increase in $\mathrm{H} 1$ (95\% CI [2.6\%, 3.5\%]). Thus, epithelial injury was strongly correlated to the increase in $\mathrm{H}$, a measure of alveolar derecruitment. Furthermore, injury only occurred when the animals were ventilated with high plateau pressures and zero PEEP.

\section{Discussion}

By analyzing SEM images selected using an unbiased sampling method, we have shown that both high inspiratory plateau pressures and very low PEEP are necessary to cause physical damage to the alveolar epithelium of initially healthy mice that is identifiable via SEM. Neither high plateau pressures with PEEP $=3 \mathrm{cmH}_{2} \mathrm{O}$ nor low pressures with or without PEEP produced observable damage to the epithelial surface (Figs. 3, 4A, and 4B).

Furthermore, the extent of epithelial damage was tightly linked to derangements in lung mechanical function (Fig. 6). Importantly, our SEM images show destruction or detachment of some cells while adjacent cells remain intact (white arrows in Fig. 4). This cellular-scale injury heterogeneity has also been demonstrated in TEM investigations of ARDS in humans (Bachofen and Weibel, 1977) as well as in animal models of lung injury (Hirai et al., 1977; Kapanci et al., 1969; Velazquez et al., 1991; Woods et al., 1993) and VILI (Dreyfuss et al., 1985; Dreyfuss et al., 1988). Importantly, we observed widespread epithelial surface damage only during ventilation with high inspiratory pressures and ZEEP, as previously demonstrated with TEM (Dreyfuss et al., 1988). These conditions favor cyclic alveolar collapse and reopening and support the notion that atelectrauma plays an important role in injuring the epithelial side of the blood-gas barrier.

The strong correlation between alveolar collapse quantified by the increase in $\mathrm{H}$ and visual evidence of widespread epithelial injury (Fig. 6) is presumably due to leakage of plasmaderived fluid and proteins through the compromised blood-gas barrier: the bigger the leak, the more material accumulates in the airspaces during a given time. A strong correlation between TEM observations of alveolar epithelial disruption and alveolar leak assessed with positron emission tomography in oleic acid injured dogs supports this inference (Velazquez et al., 1991), as does our previous study demonstrating a strong link between leak of FICTlabelled dextran into the airspaces and derangements in lung function in mice with VILI (Smith et al., 2017). Further support for the relationship between alveolar surface damage and leak is provided by TEM observations of epithelial surface disruption and edema in initially healthy rats (Dreyfuss and Saumon, 1993). Together with cellular debris, this accumulated material impairs the activity of pulmonary surfactant and thus causes significant derangements in lung function (Massa et al., 2008; Smith et al., 2015). Despite the fact that the pattern of injury was quite patchy, with normal epithelial cells adjacent to denuded areas in a single alveolus, a single damaged cell is apparently sufficient to flood the alveolus, and this proteinaceous material may be squeezed into adjacent undamaged alveoli during ventilation (Velazquez et al., 1991). Note that we do not see all of this material in our SEM images because the lungs were fixed by instillation of fixative through the airways. 
This no doubt washed at least some of the loose material out of the alveoli, but was necessary in order to obtain an unfettered look at the epithelial surface. Nevertheless, the injured alveoli were characterized by the presence of debris adhered to the epithelial surface as reported in other electron microscopy studies where fixative was instilled into the airspace (Bachofen and Weibel, 1977; Dreyfuss and Saumon, 1993; Velazquez et al., 1991). Significant fluid and debris were seen when we prepared lungs for SEM by perfusion fixation through the pulmonary vasculature (data not shown), but this prevented direct visualization of the alveolar surface.

Previous animal studies of VILI have demonstrated alveolar cell membrane disruption through uptake of propidium iodide (Gajic et al., 2003; Hussein et al., 2013) or ethidium homodimer-1 (Pecchiari et al., 2012) and epithelial injury through presence of epithelial components such as e-cadherin in the bronchoalveolar lavage fluid (Thammanomai et al., 2007) and through qualitative TEM observations (Dreyfuss et al., 1985; Dreyfuss et al., 1988; John et al., 1982; Vaneker et al., 2007). The SEM images of the present study complement these previous observations by providing a unique visual depiction of the heterogeneous nature of this physical damage to the alveolar epithelial barrier. The data from the HighP/ZEEP/2 $\times$ H group (Fig. 5B) suggest that VILI began in the mice at the lung apices and then propagated downward along the cranial-caudal axis. Alveolar surface damage was frequently observed near the pleural surface but there was no preference for dorsal, ventral, medial, or lateral quadrants of the lung, and there was no consistent pattern of damage within the plane of slices. In general, however, the damage was distributed throughout the lung, implying that atelectrauma was similarly widespread. Our study was motivated by the notion that volutrauma and atelectrauma ought to adversely affect the epithelial barrier in different ways because the mechanical stresses they impart are markedly different. We had initially wondered whether alveolar overdistension might pull the epithelial cells apart at the seams where they are joined by tight junctions, which has been studied computationally (Hamlington et al., 2016) and in vitro (Cavanaugh and Margulies, 2002; Cavanaugh et al., 2001), particularly as the large pressure gradients that occur during recruitment have been shown in vitro to cause necrosis as a result of physical damage to the cells themselves (Bilek et al., 2003; Kay et al., 2004; Yalcin et al., 2007). Interestingly, it seems that volutrauma damages the cells themselves rather than their junctions.

As in our prior studies (Allen et al., 2002; Massa et al., 2008; Seah et al., 2011; Smith and Bates, 2013; Smith et al., 2013; Smith et al., 2015), we quantified the functional consequences of VILI using derecruitability tests (Fig. 2). These measurements demonstrate that derecruitment is a function not only of pressure but also of time, and that both the amount of derecruitment and the rate at which it develops are sensitive indicators of the degree of lung injury (Smith et al., 2015). We have found in previous studies in mice that increased derecruitability occurs with high $\mathrm{V}_{\mathrm{T}}$ ventilation in the presence of zero PEEP (Seah et al., 2011; Smith et al., 2013), which is consistent with the patterns of physical damage and functional degradation seen in the present study. Importantly, exposing normal lungs to high ventilation pressures without allowing derecruitment to occur at the end of every breath does not cause progressive development of epithelial injury in the relatively short duration of our experiments. It seems, therefore, that atelectrauma is the key to the early initiation of epithelial injury, at least in initially healthy mice. A possible biophysical 
mechanism responsible for this injury is the large normal stress gradient that is produced at the air-liquid interface of a migrating bubble as it moves over the epithelial surface; repetitive applications of these stresses have been shown to lead to rapid cell damage and death in vitro (Bilek et al., 2003; Glindmeyer et al., 2012; Kay et al., 2004). Repetitive recruitment and derecruitment are also necessary to produce the major lung function derangements associated with VILI in vivo. Pigs and rats subjected to airway pressure release ventilation do not develop these derangements unless the release time is long enough to allow derecruitment of the lung to occur (Kollisch-Singule et al., 2015; Kollisch-Singule et al., 2014a; Kollisch-Singule et al., 2014b; Roy et al., 2013; Smith et al., 2015). Similarly, high $\mathrm{V}_{\mathrm{T}}$ liquid ventilation of rat lungs, in which there is no air-liquid interface and therefore no surface tension, produces only minor epithelial cell wounding whereas significant cell injury occurs in initially flooded lungs ventilated with air to equivalent levels of distension at zero PEEP (Hussein et al., 2013).

However, it is important to note that absence of overt epithelial damage is not necessarily equivalent to VILI. For example, high inflation pressures with PEEP may disrupt the endothelial barrier and lead to pulmonary edema (Dreyfuss and Saumon, 1993) as shown by TEM evidence of endothelial blebs (Dreyfuss et al., 1988), even when the alveolar epithelium is protected. In addition, the importance of inspiratory strain on ventilatorinduced inflammation cannot be overlooked; there is a substantial body of evidence demonstrating increased inflammatory markers with elevated tidal or peak strains (Gonzalez-Lopez et al., 2012; Parsons et al., 2005; Wellman et al., 2014). Because inflammation is associated with increased morbidity and mortality (Parsons et al., 2005), it is clearly important to consider the systemic effects of mechanical ventilation along with its local cellular-level consequences.

Interestingly, as in our previous studies in mice (Massa et al., 2008), ZEEP did not cause degradation of lung function when $\mathrm{V}_{\mathrm{T}}$ was low (Figs. 2 and 6); both high plateau pressure and ZEEP were necessary to cause damage to the epithelial surface. This suggests that an injury threshold exists for lung tissue distension at ZEEP, as has been reported for initially healthy pigs (Cressoni et al., 2016; Protti et al., 2015; Protti et al., 2011) and rats (de Prost et al., 2007; Dreyfuss and Saumon, 1998b). The idea that low $\mathrm{V}_{\mathrm{T}}$ and ZEEP avoid overdistension-induced injury is straightforward. In addition, it is possible that atelectrauma is also reduced because once the lungs derecruit at ZEEP, they remain derecruited until inspiratory pressure exceeds some threshold value that lies above the plateau pressure produced by a low $\mathrm{V}_{\mathrm{T}}$. This might partially explain the protective effects of low $\mathrm{V}_{\mathrm{T}}$ (ARDSnet, 2000) and of reduced driving pressures (Amato et al., 2015), both of which are conventionally attributed to reductions in cyclic or peak tissue strain. Another plausible explanation for the apparent synergy we observed between high $\mathrm{V}_{\mathrm{T}}$ and ZEEP is that spatial heterogeneity caused by regional derecruitment increases local alveolar strain in the vicinity of collapsed regions of the lung (Kollisch-Singule et al., 2016; Makiyama et al., 2014; Mead et al., 1970; Suki and Hubmayr, 2014; Wu et al., 2014), leading to damage in those regions that then propagates outward as injury progresses. A third possibility is that high $\mathrm{V}_{\mathrm{T}}$ and ZEEP together impair surfactant function in initially healthy lungs (Albert, 2012), resulting in increased surface tension that initiates the positive feedback between increasing stress and injury. The issue remains poorly understood. 
Our study has a number of limitations that must be acknowledged. First, very high $\mathrm{V}_{\mathrm{T}}$ and ZEEP are never simultaneously imposed on patients, so the way we instigated VILI in the present study does not recapitulate a clinical situation. We used this approach merely as a means of generating a titratable level of tissue injury in initially healthy animals. On the other hand, once VILI was present, the high ventilation pressures we used effectively represented the use of a normal $\mathrm{V}_{\mathrm{T}}$ on a highly derecruited lung (Gattinoni et al., 2016; Gattinoni and Pesenti, 2005), something that can potentially occur clinically. Likewise, higher PEEPs used in the clinic may allow similar degrees of derecruitment to ZEEP in the healthy lung. Another limitation of our study is that we focused entirely on the epithelial side of the blood-gas barrier. Clearly, the endothelial side must also be damaged if significant amounts of plasma-derived material are to find their way into the alveolar airspaces, and endothelial detachment and blebs during VILI have been documented via TEM (Dreyfuss et al., 1985; Dreyfuss et al., 1988; Vaneker et al., 2007). Figure 6 demonstrates a linear correlation between pulmonary system elastance and the percentage of alveoli with visually apparent surface damage. In a previous study of mice subjected to ventilation protocols similar to those of the present study (Smith et al., 2017) we observed that elastance was linearly correlated with both the total protein content of bronchoalveolar lavage fluid and with the amount of intravenously injected fluorescent tracer in the airspaces. These previous observations demonstrate compromised integrity of the aveolocapillary membrane, of which the endothelial barrier is a component. In another previous study (Hamlington et al., 2018), however, we found that a significant number of lung cells suffered from membrane disruption, as quantified by positive staining for intravenously injected propidium iodide, during HighP/PEEP ventilation. Because the alveolar surface of mice subject to HighP/PEEP ventilation in the present study did not exhibit significant signs of damage, the propidium iodide positive cells in our previous study likely represent endothelial damage, which is in agreement with prior TEM observations by others of endothelial blebs and detachment during high pressure ventilation with PEEP (Dreyfuss et al., 1988). Furthermore, a previous SEM study in rabbits subjected to high capillary pressures demonstrated narrow breaks in the alveolar surface (Costello et al., 1992), a phenomenon we occasionally observed in our VILI mice. Damaging forces originating at the vascular side of the barrier can therefore affect the integrity of the airway epithelium, which constitutes the last line of defense against alveolar leak.

It has also been shown that damaged epithelial cells can spontaneously heal if their injury is not overwhelming (Gajic et al., 2003; Godin et al., 2011; Hussein et al., 2013), so it is possible that the apparently non-injurious modes of ventilation used in the present study did in fact cause some injury that was reversed by the time we fixed the lungs for study. Of course, it must also be remembered that our study was performed in animals with initially normally lungs; there is strong evidence that the roles of volutrauma versus atelectrauma are different in lungs that have a pre-existing level of injury (Dreyfuss and Saumon, 1998a). Finally, by studying mice, we limited ourselves to tiny lungs in which the effects of gravitational gradients are negligible, in contrast to large animals that experience substantial gravity-dependent strain gradients along the dorsal-ventral axis (Paula et al., 2016). Also, several studies show that VILI develops more rapidly in small as compared to large animals and probably also humans (Dreyfuss and Saumon, 1998a), so the timescale over which we 
have characterized the effects of volutrauma versus atelectrauma in the present study may need to be dilated to be applicable to human patients.

\section{Conclusion}

Injurious mechanical ventilation with high inspiratory pressure and zero PEEP leads to severe injury to the alveolar epithelium that compromises the integrity of the blood-gas barrier. The spatially heterogeneous damage appears to be to the cells themselves rather than the intercellular junctions, and this injury is closely linked to changes in lung function indicative of alveolar collapse. Furthermore, the widespread epithelial damage caused by injurious mechanical ventilation in initially healthy lungs occurs only with ZEEP and thus appears to be associated primarily with atelectrauma rather than volutrauma. This finding suggests that the avoidance of repetitive recruitment of the lung should be a component of protective ventilation strategies so long as the addition of PEEP does not result in injurious overdistension.

\section{Acknowledgments}

This work was supported by the National Institutes of Health grants HL-076122, HL-124052, and HL-128944. The authors thank Michele von Turkovich and Douglas Taatjes for technical support and services in the Microscopy Imaging Center of the University of Vermont.

\section{References}

Albert RK. The role of ventilation-induced surfactant dysfunction and atelectasis in causing acute respiratory distress syndrome. Am J Respir Crit Care Med. 2012; 185:702-708. [PubMed: 22227381]

Allen G, Lundblad LKA, Parsons P, Bates JHT. Transient mechanical benefits of a deep inflation in the injured mouse lung. J Appl Physiol. 2002; 93:1709-1715. [PubMed: 12381758]

Amato MB, Meade MO, Slutsky AS, Brochard L, Costa EL, Schoenfeld DA, Stewart TE, Briel M, Talmor D, Mercat A, Richard JC, Carvalho CR, Brower RG. Driving pressure and survival in the acute respiratory distress syndrome. The New England journal of medicine. 2015; 372:747-755. [PubMed: 25693014]

ARDSnet. Ventilation with lower tidal volumes as compared with traditional tidal volumes for acute lung injury and the acute respiratory distress syndrome. New Engl J Med. 2000; 342:1301-1308. [PubMed: 10793162]

Bachofen M, Weibel ER. Alterations of the gas exchange apparatus in adult respiratory insufficiency associated with septicemia. Am Rev Respir Dis. 1977; 116:589-615. [PubMed: 921049]

Bilek AM, Dee KC, Gaver DP. Mechanisms of surface-tension-induced epithelial cell damage in a model of pulmonary airway reopening. J Appl Physiol. 2003; 94:770-783. [PubMed: 12433851]

Cavanaugh KJ Jr, Margulies SS. Measurement of stretch-induced loss of alveolar epithelial barrier integrity with a novel in vitro method. American journal of physiology Cell physiology. 2002; 283:C1801-1808. [PubMed: 12388082]

Cavanaugh KJ Jr, Oswari J, Margulies SS. Role of stretch on tight junction structure in alveolar epithelial cells. Am J Resp Cell Mol. 2001; 25:584-591.

Costello ML, Mathieu-Costello O, West JB. Stress failure of alveolar epithelial cells studied by scanning electron microscopy. Am Rev Respir Dis. 1992; 145:1446-1455. [PubMed: 1596017]

Cressoni M, Gotti M, Chiurazzi C, Massari D, Algieri I, Amini M, Cammaroto A, Brioni M, Montaruli C, Nikolla K, Guanziroli M, Dondossola D, Gatti S, Valerio V, Vergani GL, Pugni P, Cadringher P, Gagliano N, Gattinoni L. Mechanical Power and Development of Ventilator-induced Lung Injury. Anesthesiology. 2016; 124:1100-1108. [PubMed: 26872367] 
de Prost N, Dreyfuss D, Saumon G. Evaluation of two-way protein fluxes across the alveolo-capillary membrane by scintigraphy in rats: effect of lung inflation. J Appl Physiol. 2007; 102:794-802. [PubMed: 16990504]

Dreyfuss D, Basset G, Soler P, Saumon G. Intermittent positive-pressure hyperventilation with high inflation pressures produces pulmonary microvascular injury in rats. Am Rev Respir Dis. 1985; 132:880-884. [PubMed: 3901844]

Dreyfuss D, Saumon G. Role of tidal volume, FRC, and end-inspiratory volume in the development of pulmonary edema following mechanical ventilation. Am Rev Respir Dis. 1993; 148:1194-1203. [PubMed: 8239153]

Dreyfuss D, Saumon G. Ventilator-induced lung injury: lessons from experimental studies. Am J Respir Crit Care Med. 1998a; 157:294-323. [PubMed: 9445314]

Dreyfuss D, Saumon G. Ventilator-induced lung injury: lessons from experimental studies. Am J Respir Crit Care Med. 1998b; 157:294-323. [PubMed: 9445314]

Dreyfuss D, Soler P, Basset G, Saumon G. High inflation pressure pulmonary edema. Respective effects of high airway pressure, high tidal volume, and positive end-expiratory pressure. Am Rev Respir Dis. 1988; 137:1159-1164. [PubMed: 3057957]

Gajic O, Lee J, Doerr CH, Berrios JC, Myers JL, Hubmayr RD. Ventilator-induced cell wounding and repair in the intact lung. Am J Resp Crit Care. 2003; 167:1057-1063.

Gattinoni L, Marini JJ, Pesenti A, Quintel M, Mancebo J, Brochard L. The "baby lung" became an adult. Intensive Care Med. 2016; 42:663-673. [PubMed: 26781952]

Gattinoni L, Pesenti A. The concept of "baby lung”. Intensive Care Med. 2005; 31:776-784. [PubMed: 15812622]

Gattinoni L, Protti A, Caironi P, Carlesso E. Ventilator-induced lung injury: the anatomical and physiological framework. Critical care medicine. 2010; 38:S539-548. [PubMed: 21164395]

Glindmeyer, HWt, Smith, BJ., Gaver, DP, 3rd. In situ enhancement of pulmonary surfactant function using temporary flow reversal. J Appl Physiol (1985). 2012; 112:149-158. [PubMed: 21998268]

Godin LM, Vergen J, Prakash YS, Pagano RE, Hubmayr RD. Spatiotemporal dynamics of actin remodeling and endomembrane trafficking in alveolar epithelial type 1 cell wound healing. American journal of physiology Lung cellular and molecular physiology. 2011; 300:L615-623. [PubMed: 21216977]

Gonzalez-Lopez A, Garcia-Prieto E, Batalla-Solis E, Amado-Rodriguez L, Avello N, Blanch L, Albaiceta GM. Lung strain and biological response in mechanically ventilated patients. Intensive Care Med. 2012; 38:240-247. [PubMed: 22109653]

Hamlington KL, Bates JHT, Roy GS, Julianelle AJ, Charlebois C, Suki B, Smith BJ. Alveolar leak develops by a rich-get-richer process in ventilator-induced lung injury. Plos One. 2018; 13:e0193934. [PubMed: 29590136]

Hamlington KL, Ma B, Smith BJ, Bates JHT. Modeling the Progression of Epithelial Leak Caused by Overdistension. Cellular and Molecular Bioengineering. 2016; 9:151-161. [PubMed: 26951764]

Hantos Z, Daroczy B, Suki B, Nagy S, Fredberg JJ. Input impedance and peripheral inhomogeneity of dog lungs. J Appl Physiol (1985). 1992; 72:168-178. [PubMed: 1537711]

Hirai KI, Witschi H, Cote MG. Electron microscopy of butylated hydroxytoluene-induced lung damage in mice. Exp Mol Pathol. 1977; 27:295-308. [PubMed: 923747]

Hussein O, Walters B, Stroetz R, Valencia P, McCall D, Hubmayr RD. Biophysical determinants of alveolar epithelial plasma membrane wounding associated with mechanical ventilation. American journal of physiology Lung cellular and molecular physiology. 2013; 305:L478-484. [PubMed: 23997173]

John E, McDevitt M, Wilborn W, Cassady G. Ultrastructure of the lung after ventilation. Br J Exp Pathol. 1982; 63:401-407. [PubMed: 7150503]

Kapanci Y, Weibel ER, Kaplan HP, Robinson FR. Pathogenesis and reversibility of the pulmonary lesions of oxygen toxicity in monkeys. II. Ultrastructural and morphometric studies. Lab Invest. 1969; 20:101-118. [PubMed: 4988417]

Kay SS, Bilek AM, Dee KC, Gaver DP. Pressure gradient, not exposure duration, determines the extent of epithelial cell damage in a model of pulmonary airway reopening. J Appl Physiol. 2004; 97:269-276. [PubMed: 15004001] 
Kollisch-Singule M, Emr B, Jain SV, Andrews P, Satalin J, Liu J, Porcellio E, Kenyon V, Wang G, Marx W, Gatto LA, Nieman GF, Habashi NM. The effects of airway pressure release ventilation on respiratory mechanics in extrapulmonary lung injury. Intensive care medicine experimental. $2015 ; 3: 35$.

Kollisch-Singule M, Emr B, Smith B, Roy S, Jain S, Satalin J, Snyder K, Andrews P, Habashi N, Bates J, Marx W, Nieman G, Gatto LA. Mechanical breath profile of airway pressure release ventilation: the effect on alveolar recruitment and microstrain in acute lung injury. JAMA Surg. 2014a; 149:1138-1145. [PubMed: 25230047]

Kollisch-Singule M, Emr B, Smith B, Ruiz C, Roy S, Meng Q, Jain S, Satalin J, Snyder K, Ghosh A, Marx WH, Andrews P, Habashi N, Nieman GF, Gatto LA. Airway pressure release ventilation reduces conducting airway micro-strain in lung injury. J Am Coll Surg. 2014b; 219:968-976. [PubMed: 25440027]

Kollisch-Singule M, Jain S, Andrews P, Smith BJ, Hamlington-Smith KL, Roy S, DiStefano D, Nuss E, Satalin J, Meng Q, Marx W, Bates JH, Gatto LA, Nieman GF, Habashi NM. Effect of Airway Pressure Release Ventilation on Dynamic Alveolar Heterogeneity. JAMA Surg. 2016; 151:64-72. [PubMed: 26444302]

Lutz D, Gazdhar A, Lopez-Rodriguez E, Ruppert C, Mahavadi P, Gunther A, Klepetko W, Bates JH, Smith B, Geiser T, Ochs M, Knudsen L. Alveolar Derecruitment and Collapse Induration as Crucial Mechanisms in Lung Injury and Fibrosis. Am J Resp Cell Mol. 2015; 52:232-243.

Makiyama AM, Gibson LJ, Harris RS, Venegas JG. Stress concentration around an atelectatic region: a finite element model. Respiratory physiology \& neurobiology. 2014; 201:101-110. [PubMed: 25048678]

Massa CB, Allen GB, Bates JHT. Modeling the dynamics of recruitment and derecruitment in mice with acute lung injury. J Appl Physiol. 2008; 105:1813-1821. [PubMed: 18948446]

Mead J, Takishima T, Leith D. Stress distribution in lungs: a model of pulmonary elasticity. J Appl Physiol. 1970; 28:596-608. [PubMed: 5442255]

Parsons PE, Eisner MD, Thompson BT, Matthay MA, Ancukiewicz M, Bernard GR, Wheeler AP. Network, N.A.R.D.S.C.T. Lower tidal volume ventilation and plasma cytokine markers of inflammation in patients with acute lung injury. Critical care medicine. 2005; 33:1-6. discussion 230-232. [PubMed: 15644641]

Paula LF, Wellman TJ, Winkler T, Spieth PM, Guldner A, Venegas JG, Gama de Abreu M, Carvalho AR, Vidal Melo MF. Regional Tidal Lung Strain in Mechanically Ventilated Normal Lungs. J Appl Physiol (1985). 2016; 121:1335-1347. [PubMed: 27445302]

Pecchiari M, Monaco A, Koutsoukou A, D'Angelo E. Plasma membrane disruptions with different modes of injurious mechanical ventilation in normal rat lungs*. Critical care medicine. 2012; 40:869-875. [PubMed: 22001586]

Protti A, Andreis DT, Milesi M, Iapichino GE, Monti M, Comini B, Pugni P, Melis V, Santini A, Dondossola D, Gatti S, Lombardi L, Votta E, Carlesso E, Gattinoni L. Lung anatomy, energy load, and ventilator-induced lung injury. Intensive care medicine experimental. 2015; 3:34. [PubMed: 26671060]

Protti A, Cressoni M, Santini A, Langer T, Mietto C, Febres D, Chierichetti M, Coppola S, Conte G, Gatti S, Leopardi O, Masson S, Lombardi L, Lazzerini M, Rampoldi E, Cadringher P, Gattinoni L. Lung Stress and Strain during Mechanical Ventilation Any Safe Threshold? Am J Resp Crit Care. 2011; 183:1354-1362.

Roy S, Habashi N, Sadowitz B, Andrews P, Ge L, Wang G, Roy P, Ghosh A, Kuhn M, Satalin J, Gatto LA, Lin X, Dean DA, Vodovotz Y, Nieman G. Early airway pressure release ventilation prevents ARDS-a novel preventive approach to lung injury. Shock. 2013; 39:28-38. [PubMed: 23247119]

Schneider, JP., Ochs, M. Chapter 12 - Stereology of the Lung. In: Conn, PM., editor. Methods in Cell Biology. Academic Press; 2013. p. 257-294.

Seah AS, Grant KA, Aliyeva M, Allen GB, Bates JHT. Quantifying the roles of tidal volume and PEEP in the pathogenesis of ventilator-induced lung injury. Ann Biomed Eng. 2011; 39:1505-1516. [PubMed: 21203845] 
Smith BJ, Bartolak-Suki E, Suki B, Roy GS, Hamlington KL, Charlebois CM, Bates JHT. Linking Ventilator Injury-Induced Leak across the Blood-Gas Barrier to Derangements in Murine Lung Function. Front Physiol. 2017; 8:466. [PubMed: 28736528]

Smith BJ, Bates JHT. Assessing the Progression of Ventilator-Induced Lung Injury in Mice. Ieee T Bio-Med Eng. 2013; 60:3449-3457.

Smith BJ, Grant KA, Bates JHT. Linking the development of ventilator-induced injury to mechanical function in the lung. Ann Biomed Eng. 2013; 41:527-536. [PubMed: 23161164]

Smith BJ, Lundblad LKA, Kollisch-Singule M, Satalin J, Nieman G, Habashi N, Bates JHT. Predicting the response of the injured lung to the mechanical breath profile. J Appl Physiol. 2015; 118:932940. [PubMed: 25635004]

Suki B, Hubmayr R. Epithelial and endothelial damage induced by mechanical ventilation modes. Curr Opin Crit Care. 2014; 20:17-24. [PubMed: 24300621]

Thammanomai A, Majumdar A, Bartolak-Suki E, Suki B. Effects of reduced tidal volume ventilation on pulmonary function in mice before and after acute lung injury. J Appl Physiol. 2007; 103:15511559. [PubMed: 17690203]

Vaneker M, Halbertsma FJ, van Egmond J, Netea MG, Dijkman HB, Snijdelaar DG, Joosten LA, van der Hoeven JG, Scheffer GJ. Mechanical ventilation in healthy mice induces reversible pulmonary and systemic cytokine elevation with preserved alveolar integrity: an in vivo model using clinical relevant ventilation settings. Anesthesiology. 2007; 107:419-426. [PubMed: 17721244]

Velazquez M, Weibel ER, Kuhn C, Schuster DP 3rd. PET evaluation of pulmonary vascular permeability: a structure-function correlation. J Appl Physiol (1985). 1991; 70:2206-2216. [PubMed: 1864802]

Wellman TJ, Winkler T, Costa EL, Musch G, Harris RS, Zheng H, Venegas JG, Vidal Melo MF. Effect of local tidal lung strain on inflammation in normal and lipopolysaccharide-exposed sheep. Critical care medicine. 2014; 42:e491-500. [PubMed: 24758890]

Woods LW, Wilson DW, Schiedt MJ, Giri SN. Structural and biochemical changes in lungs of 3methylindole-treated rats. Am J Pathol. 1993; 142:129-138. [PubMed: 8424451]

Wu Y, Kharge AB, Perlman CE. Lung ventilation injures areas with discrete alveolar flooding, in a surface tension-dependent fashion. J Appl Physiol (1985). 2014; 117:788-796. [PubMed: 25080924]

Yalcin HC, Perry SF, Ghadiali SN. Influence of airway diameter and cell confluence on epithelial cell injury in an in vitro model of airway reopening. J Appl Physiol (1985). 2007; 103:1796-1807. [PubMed: 17673567] 


\section{Highlights}

- Degradation in lung function linked to injury of the alveolar epithelium observed by SEM

- $\quad$ Both high inspiratory plateau pressure and zero PEEP required to cause lung injury

- Epithelial injury tightly associated with alveolar collapse

- Damage to the epithelium attributable to ventilator-induced lung injury 


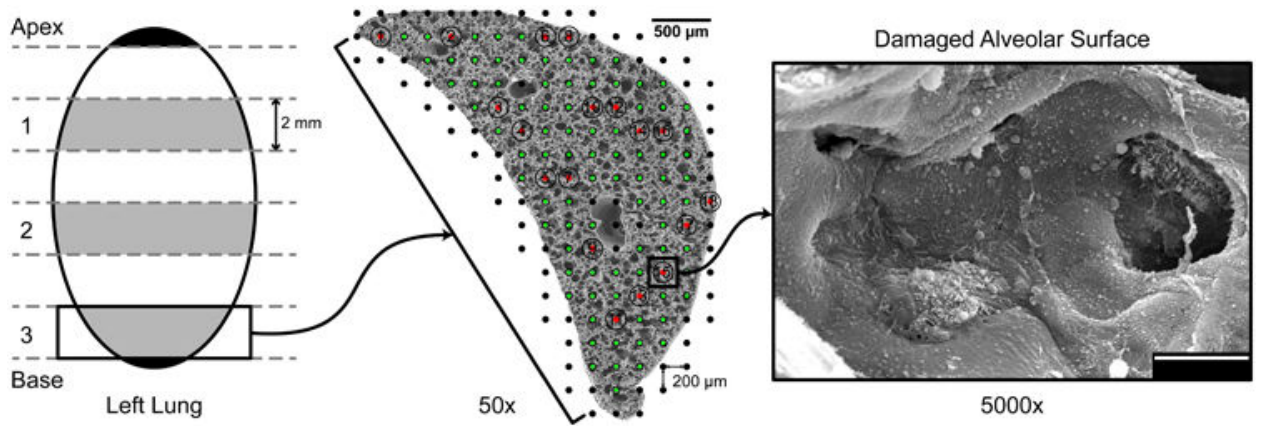

Fig 1.

Sampling scheme of mouse lung slices for scanning electron microscopy. Uniform random sampling was used to select 3 slices from the left lung and 18 fields of view, with the first of each selected by a random number generator. 


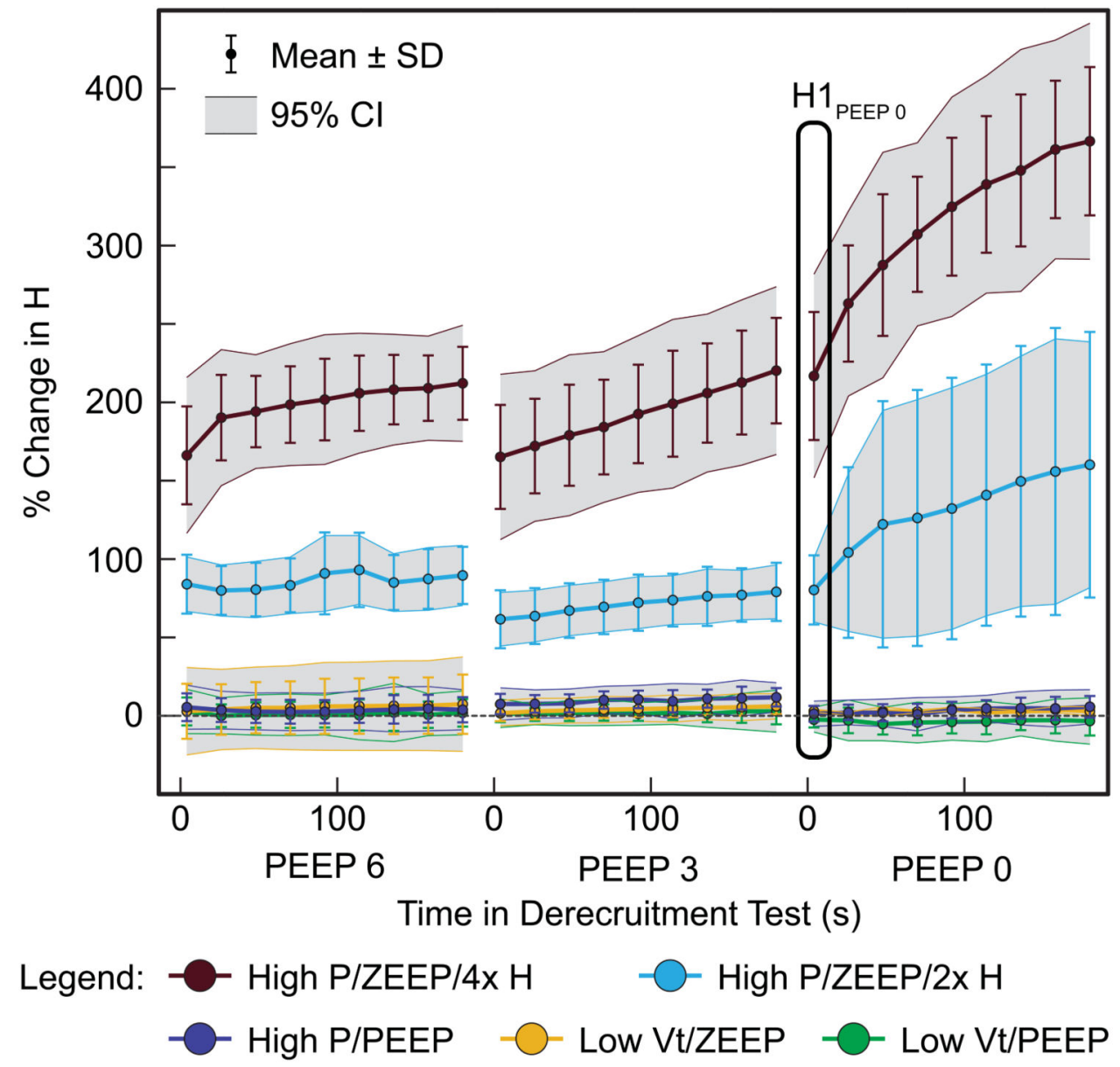

Fig 2.

Degradation in lung function. The percent change in elastance $(\mathrm{H})$ measured in derecruitment tests at PEEP $=6,3$ and $0 \mathrm{cmH}_{2} \mathrm{O}$ before and after ventilation. Increases indicate alveolar collapse. Means are significantly different with $95 \%$ confidence between groups with non-overlapping intervals. Refer to Table 1 for group descriptions. 

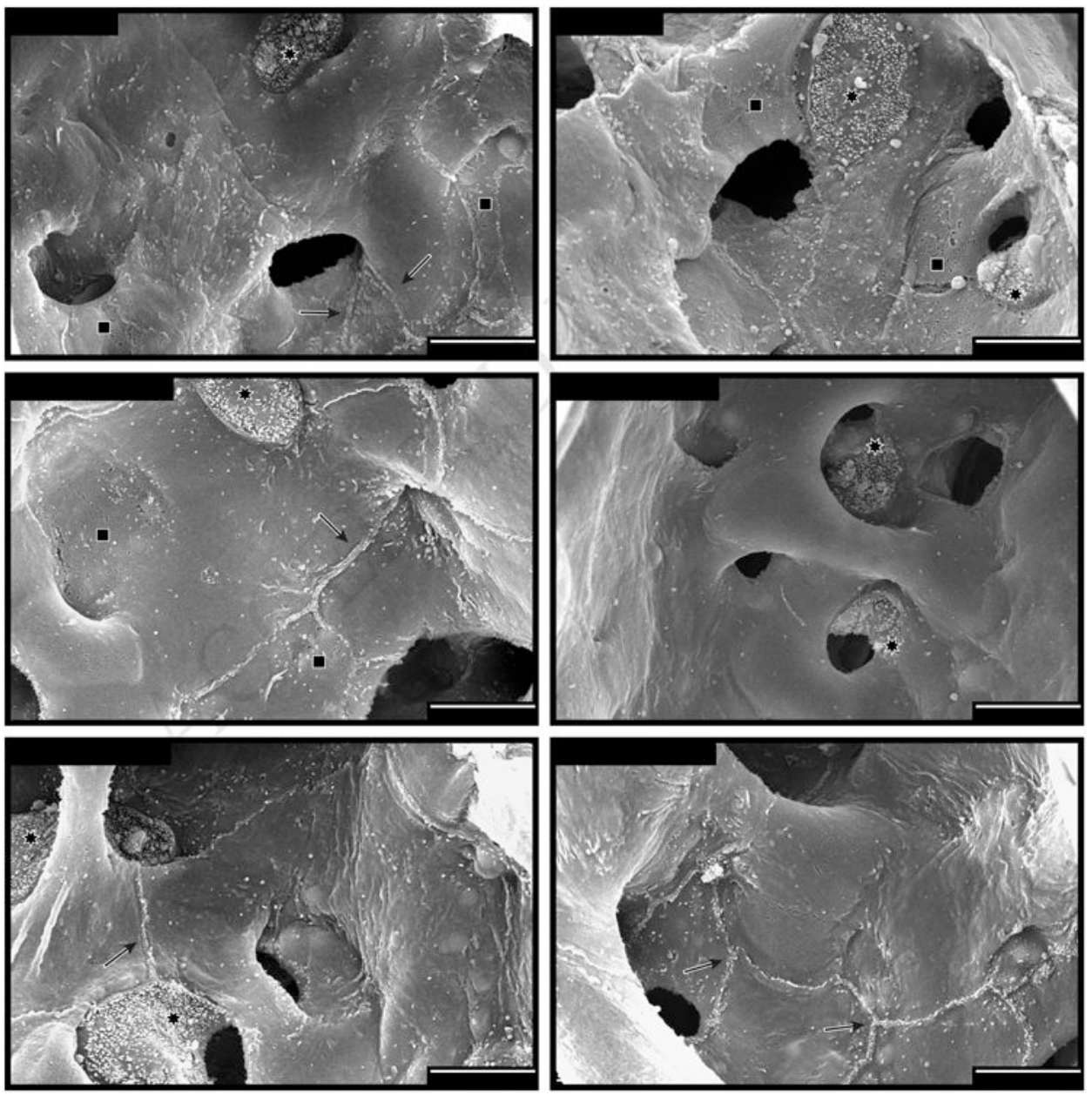

Fig. 3.

Scanning electron micrographs of the intact alveolar epithelial surface in mice. No images in the Control (panes A and B) or Low Vt/PEEP (panes C and D) groups scored positive for injury; 4 out of 216 images scored positive for injury (1.9\%) in the Low Vt/ZEEP animals (panes E and F). Note cell-cell junctions of type I alveolar cells (black arrows), type II alveolar cells $(*)$, and small holes due to fixation (black squares). 

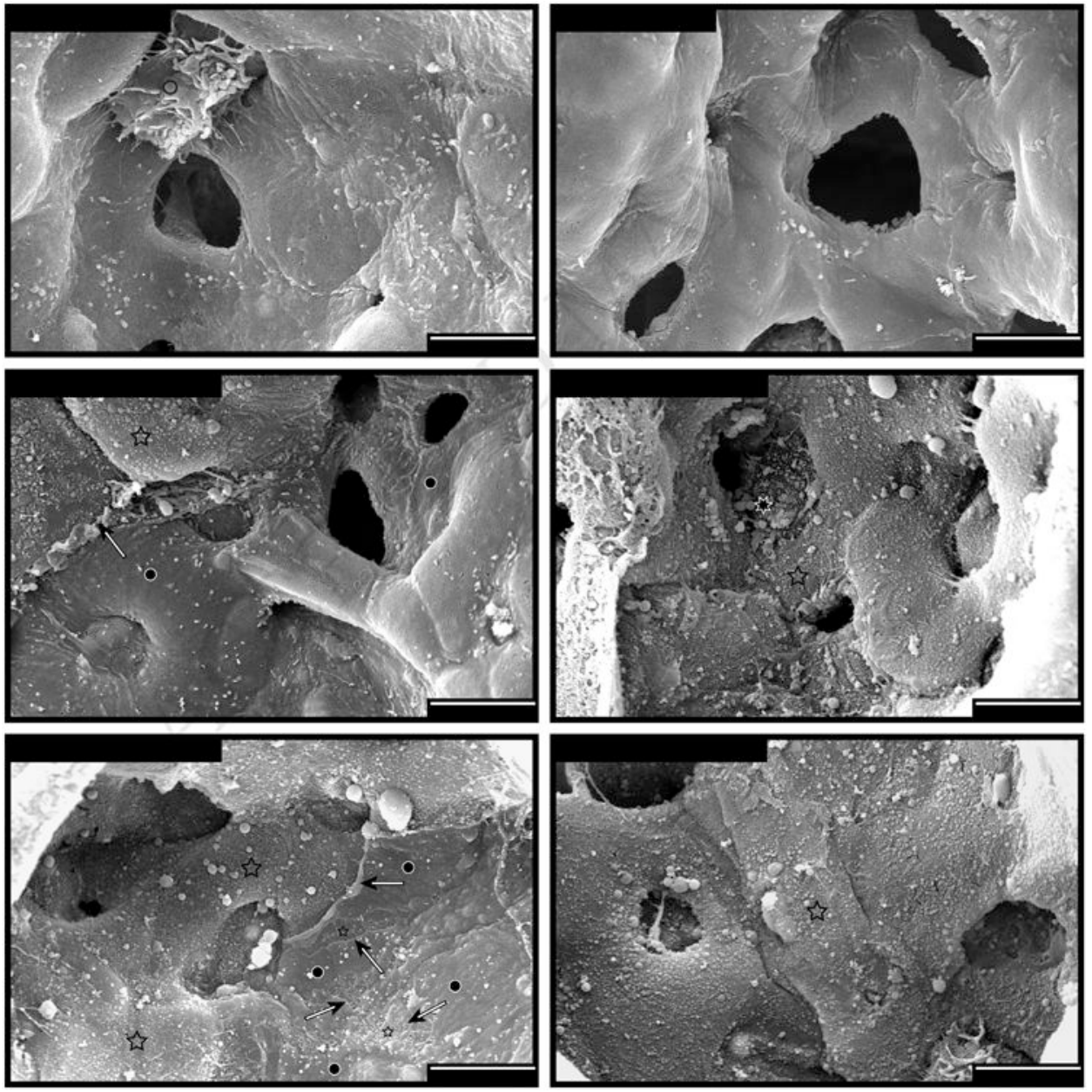

Fig. 4.

Scanning electron micrographs of the alveolar epithelial surface. Six out of 216 images scored positive for injury (2.8\%) in the High P/PEEP group (panes A and B; intact surfaces shown), whereas 137 out of 378 images (36.2\%) in the HighP/ZEEP/2×H group (panes $\mathrm{C}$ and $\mathrm{D}$; injured surfaces) and 137 out of 216 images (63.4\%) in the HighP/ZEEP/4×H group (panes E and F; injured surfaces) scored positive for injury. Symbols indicate injured epithelial surface (white stars), intact surface (black circles), type II cells (black stars), macrophage (white circle), and boundary between injured and intact epithelial surface (white arrows). 
A

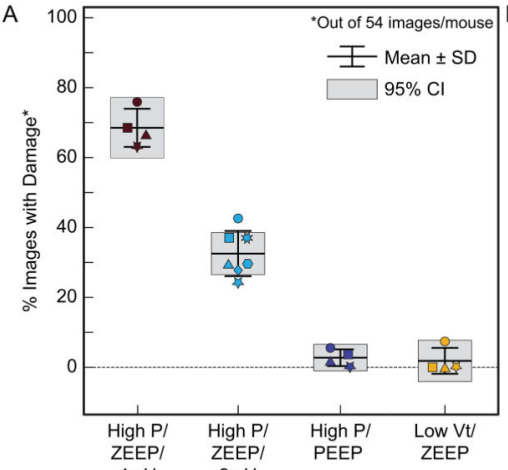

Legend: $\quad-$ High P/ZEEP/4xH - - High P/ZEEP/2x H

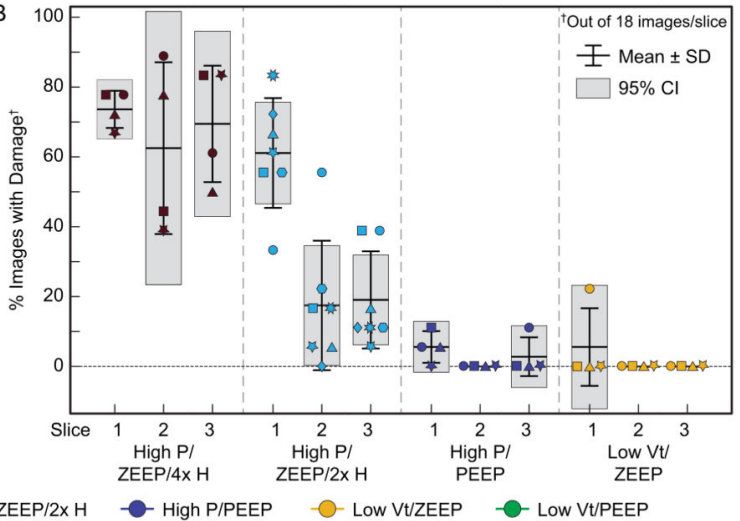

Fig. 5.

Alveolar epithelial surface injury. Mean percentage of images with damage is plotted per mouse (A) and per slice (B) with standard deviation bars and 95\% confidence intervals. In $\mathrm{B}$, the slice designation of 1,2 , and 3 corresponds to the upper, middle, and lower slices of the lung, respectively. Symbols within groups represent individual animals and are consistent between A and B. Means are significantly different with $95 \%$ confidence between groups with non-overlapping intervals. Refer to Table 1 for group descriptions. 


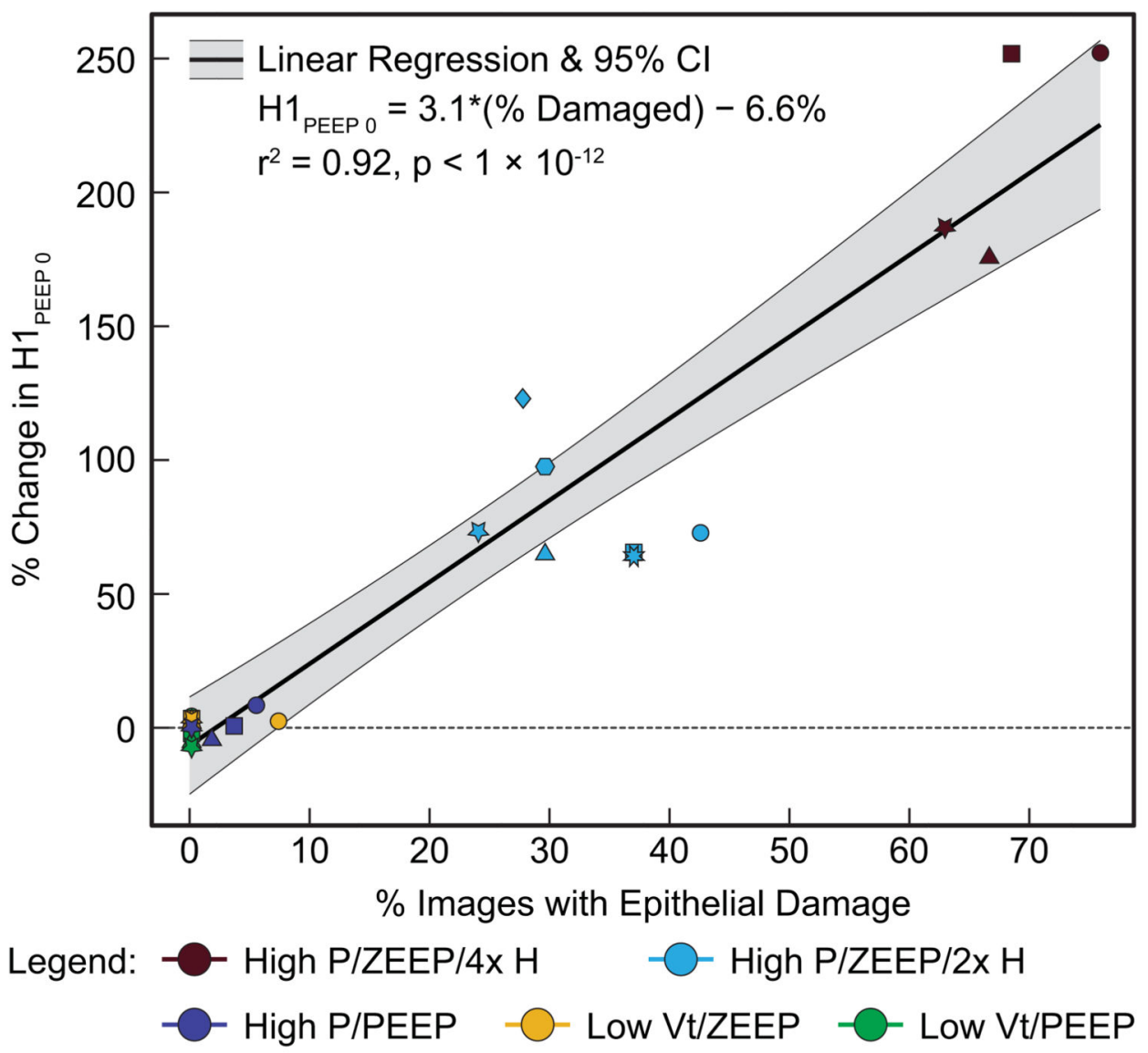

Fig. 6.

Relationship between alveolar epithelial surface injury and degradation in lung function. The linear regression between percent change in the first $\mathrm{H}$ measured at PEEP 0 ( $\mathrm{H} 1$ circled in Fig. 2) and the percentage of images with damage is plotted. Symbols within groups represent individual animals consistent with Fig. 5. Refer to Table 1 for group descriptions. 


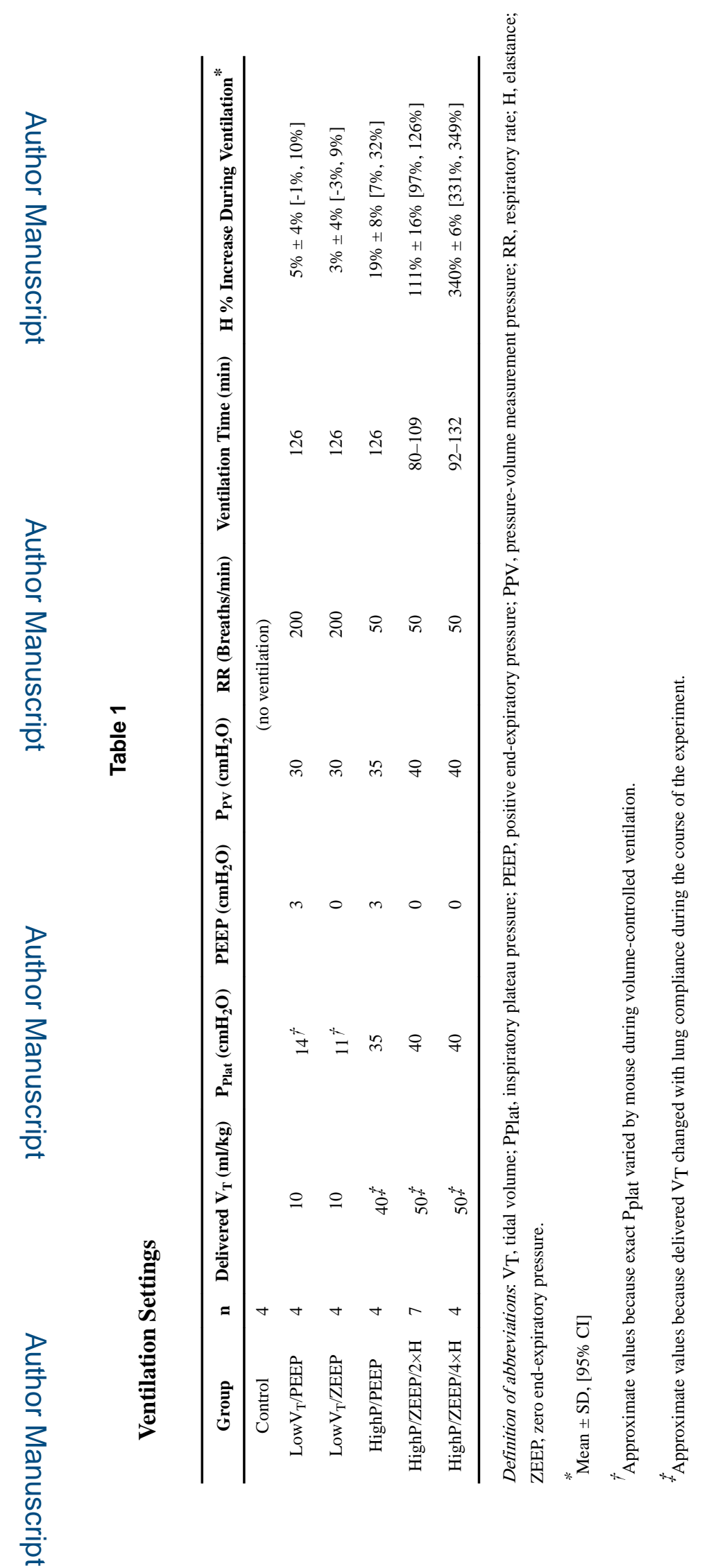

Respir Physiol Neurobiol. Author manuscript; available in PMC 2019 September 01. 